\title{
AN INVESTIGATION OF SELF-SERVICE TECHNOLOGY (SST) OF PARTICIPATION BANKING IN TURKEY
}

\section{DOI: 10.17261/Pressacademia.2017.444}

JEFA- V.-ISS.2-2017(1)-p.145-153

\author{
Waleed Mango ${ }^{1}$, Busra Muceldili ${ }^{2}$, Oya Erdil $^{3}$ \\ ${ }^{1}$ Kuveyt Türk, Istanbul, Turkey. waleedamango@gmail.com \\ ${ }^{2}$ Gebze Technical University. Kocaeli, Turkey. bmuceldili@gtu.edu.tr \\ ${ }^{3}$ Gebze Technical University. Kocaeli, Turkey. erdil@gtu.edu.tr
}

\section{To cite this document}

Mango, W., B. Muceldili and O. Erdil, (2017). An investigation of self-service technology (SST) of participation banking in Turkey. Journal of Economics, Finance and Accounting (JEFA), V.4, Iss.2, p.145-153.

Permemant link to this document: http://doi.org/10.17261/Pressacademia.2017.444

Copyright: Published by PressAcademia and limited licenced re-use rights only.

\begin{abstract}
Purpose- Scholars and practitioners have recognized the importance of the advent of technology and information technology in various industries such as supermarkets, banks, health sectors for surviving. Self-service technology (SST) is one of the important usage of technology particularly in banking industry. The aim of this study is to investigate one of the available self-service technologies in participation banking.

Methodology- The study contains a questionnaire based survey of customers from participation banking (Kuveyt Turk) operating in Turkey. A total of 165 online survey responses were used for the purposes of this study. The surveys were sent to customers of the Kuveyt Turk Participation Bank which is the only bank to use the XTM technology. Data analyzed through structural equation modelling (SEM)

Findings- The results indicate that SSTQAUL positively affects customer satisfaction and customer loyalty; customer satisfaction influences customer loyalty; customer satisfaction medaites the relationship between SSTQAUL and customer loyalty.

Conclusion- The paper emphasizes the importance of self service technolgy quality in banking industry and proposes an understanding of influneces in customer satisfaction and loyalty.
\end{abstract}

Keywords: Self-service technology, XTM, customer satisfaction, self service technology quality, banking.

JEL Codes: M31, M10

\section{INTRODUCTION}

The importance of technology has risen significantly in the last decades. Formerly, the manufacturing sector was more affected by such changes; where achieving competitive advantage is becoming harder as highly-advanced manufacturing techniques and machines are being found. Nowadays, the technology wave is affecting the service sector, specifically is appeared in the development of self-service technology development. Self-service technology refers to technological interfaces that provides direct service access without service employee involvement (Meuter, et al.,2000). The concept of self-service technology (SST) is that the employee-customer interface is no longer needed. Instead, the customer can customize his or her own service with the help of specially designed technology. Hsieh (2005) noted that there are four types of self-service technologies, namely are; telephone \& interactive voice response systems (e.g., telephone banking, flight information); interactive free standing kiosk (e.g., ATMs, hotel checkout); internet-based and online connection systems (e.g., account information, retail purchasing) and video based technologies (e.g.cd based training) (Meuter, et.al.2000). 
Advanced self-service technology is being applied in supermarkets, banks and hospitals dramatically. The concept of selfservice has been around since the 1990s, but with basic applications like Automated Teller Machines (ATM). The advent of the Internet led to the concept of Internet banking and online shopping which are other examples of self-service technology. As we entered the 21st century, computer software was integrated with smart technology in order to create more and more complex systems that help create the self-service. For example: self-checkout at supermarkets and selfcheck-in at airports.

Self-service technology has newly entered the banking sector in a different form, namely self-service bank branches. Hypothetically, in self-service branches there will be no employee-customer interaction, just a SST-customer interaction will exist. This is a very new application that has yet to be explored. There have been some attempts by a bank in the UK to make a movement towards such technology but the results are still not apparent. Turkey led by one of its major banks may as well be a pioneer in introducing such technology. It has been introduced and put into action but still has not become very widely known among the banking industry, let alone customers themselves. Technology also is one of the most important drivers of change. This is due to the fact that companies that do not withhold the status quo and do not keep up to date with the newest of technologies will eventually fail.

With the advent of smartphones, banks started providing services through smartphones. Now, it is almost impossible to find a reputable bank that does not provide banking through the Internet or mobile phone. Recently, the release of the apple watch was followed immediately with banking through your apple watch. This shows how important keeping up with recent technology is for financial institutions. Banks are always looking for the competitive edge that will help increase their market share. There are numerous technological tools in the banking industry for example, ATM, call center, mobile banking and Internet (Kahlilov \& Gündebahar, 2012). Recently a new form of SST has been used through banking industry which has been named as eXtreme Transaction Machine (XTM). This SST can be described as an advanced ATM that provides video conferencing and aims at providing the best of traditional bank branches and ATMs (Kahlilov \& Gündebahar, 2012). The XTM is actually a certain type of video teller machine (VTM). VTMs are basically ATMs that provide video and live conferencing with bank employees. XTM enable to see customer and call center operator each other's. More importantly, there is a need to measure the service quality of the XTM which is a new type of SST. Therefore, it was necessary that an appropriate model is found in order to measure the service quality of such a new type of SST.

To the best of our knowledge, this is currently applied in Kuveyt Turk Participation Bank (KTPB) in Turkey. The competition between banks has risen significantly in the last decades in the world. This is due to difficult economic times and political unrest. In such times, financial institutions are working hard to prove their stability and increase their market share. Financial crises of our times led to the conception of a new type of financial institution i.e. Participation Banks or what is also known as Islamic Banking. Participation banks are financial institutions that adhere to Islamic jurisprudence that defines certain laws and regulations that govern the transactions performed at the bank. Mainly this revolves around the prohibition of usury or interest.

After reviewing the literature for an appropriate model, the most generalizable and recent model found was the SSTQUAL. Unlike other models that focus on a certain type of self-service or channel, the SSTQUAL addresses all types of SSTs in different industries and cultures. After the emergence of the SSTQUAL scale, there have been some attempts that aim at validating the SSTQUAL in different industries and different cultures. The writers themselves urge and recommend future research to focus on validating the scale in different countries and in different industries.

Research done on the SSTQUAL is still scarce and still has not covered all the different industries and different cultures. As for Turkey, there has been a study on self-checkout systems in supermarkets. However there is yet a study to be done in the banking industry in Turkey.

We also would like to point out that the technology we researched is one of a kind. It has not been implemented on a wide scale. Thus, we aim at performing the first research of this kind on such a technology. This study helps contribute to the literature by being the first of its kind with regards to the technology researched and the niche that has been chosen. To the best our knowledge there is no research that validates the SSTQUAL for such an SST. Also, we aim to enrich the literature in the field of participation banking which is receiving growing interest in the world.

In addition, this type of validation has only been performed once within the Turkish culture but on a completely different type of SST. Previous research stresses the need to prove the validity of the SSTQUAL or any quality measurement model in different cultures because of the differences between cultures in defining quality.

The new surge in use of SSTs requires more research into how we can measure their service quality. Thus, our study aims at answering the following questions; first, which of the SSTQUAL dimensions (functionality, enjoyment, security/privacy, assurance, design, convenience, and customization) are applicable to measuring the service quality of the XTM within the participation banking industry in Turkey? Second, how do the applicable quality dimensions affect the satisfaction of customers with participation banks in Turkey? Third, how do the applicable quality dimensions affect the loyalty of 
customers towards participation banks in Turkey? And finally does the customer satisfaction with the XTM in the banking industry affect customer loyalty?

In this study, we will first explain our review of the literature related to our research questions, and then as we go on we present details regarding our hypotheses development and the methodology that led to our findings. At the end, we discuss the results, their validity and reliability. Finally, we conclude with implications of this study and refer to future research that needs to be performed.

\section{LITERATURE REVIEW AND HYPOTHESES}

\subsection{An Overview of Self-Service Technology in Banking}

Services have developed into self-services with the help of technology. Technology has a great influence on how customers view service providers and the way services are evaluated. As for the banking industry, the advent of technology and information technology has led to a great revolution. The importance of technology can be seen in many facets of the relationship between technology, customer, company and employee. It is important to note that the banking industry has thrived on the use of technology in its back-end processes and services that serve internal customers. The banking industry is also one of the first industries to see the usage of SST i.e. the invention of ATMs. It is clear that the banking industry is at the frontier when it comes to applying technology to its internal and external interactions with customers.

It is argued that the reason behind the usage of technology within the banking industry is that there is great competition in the banking industry, which forces bank management to work on reducing as much costs as possible; this is mentioned by Meuter, Bitner, Ostrom, and Brown (2005) as one of the reasons for adopting technology within the banking industry.

According to Dabholkar (1996) another underlying problem for banks is the increase in labor cost, which is one of the reasons for switching over to SST. Most banks charge their customers a fee for performing certain transactions. The ability to reduce or eliminate such fees provides great competitive advantage to the banks. For example, directing customers to using SSTs like internet banking helps banks become more cost efficient and productive (Yusuf \& Lee, 2015); or ATMs that help reduce operational costs (Akhisar et al, 2015).

As mentioned above, from an internal perspective introducing self-service technologies (SSTs) can be very lucrative for the bank and also helps reduce costs. Though SSTs have internal organizational benefits and gains, the effects they have on customers are also important. For example, customers tend to prefer a mix of delivery channels over just a single one (Howcroft, Hamilton, \& Hewer, 2002); which shows the need for firms to provide different types of SSTs along with traditional channels.

Other advantages that are gained by using the SSTs in general is that the customer has more control over the service process, which allows each customer to manage the process and guides to whatever $s /$ he expects from a banking service process quickly and conveniently. Additionally, Dabholkar (1996) mentions other benefits like enjoyment, many customers tend to find SST as enjoyable and fun to use. Customers are generally looking for service providers that help save their time and money, especially when it comes to financial services this is of great importance.

\subsection{Self- Service Technology Service Quality}

In the literature, most studies have discussed or investigated the concept of service quality of SST in different industries and countries. There are numerous studies for measuring SST service quality. It is important to note that SSTQUAL has a lot of similarities with other scales when compared. Several dimensions in previous scales are very close and resemble those of SSTQUAL. However, it is important to note that, these scales generally are focused on e-services. In this study, we follow Lin and Hsieh (2011). Because of this, SSTQUAL has been frequently used as a base model for studying different types of SSTs like self-service kiosks at supermarkets (Orel \& Kara, 2014) and SSTs used in the banking industry (Radomir \& Nistor, 2012). Accordingly, SSTQUAL have seven dimensions namely are; functionality, design, customization, enjoyment, assurance, convenience and security/privacy.

a) Functionality: is related to how well the SST functions, its responsiveness and also how easy is it to use.

b) Design: has to do with the aesthetics, look and feel of the SST.

c) Customization: relates to how well the SST is personlized and meets the specific needs of each customer.

d) Enjoyment: represents the enjoyment felt when using the SST and when the service outcome is achieved.

e) Assurance: has to do with the reputation of the SST service provider.

f) Convenience: relates to the operating conditions of the SST and how easy it is to access it.

g) Security/Privacy: is related to how secure the customer feels when using the SST and how well their privacy is being protected. 


\subsection{SST Service Quality and Customer Satisfaction}

Customer satisfaction can be defined as the positive feeling a customer feels after receiving a service (Cronin, Brady, \& Hult, 2000), or the result of the customer feeling an emotional bond to the service provider (Johnson, Sivadas, \& Garbarino, 2008). When it comes to services where there is a customer-employee interaction, satisfaction is the outcome of the process that takes place between the customer and employee during the service delivery (Meuter et al., 2000). According to this definition, customers may not feel very satisfied if this interaction with the employee is absent. This is why some might tend to prefer traditional services over SSTs even when the benefits of the SSTs are obvious (Meuter et al., 2003)

Many studies have found that service quality directly affects customer satisfaction (Akbar \& Parvez, 2009; Brady \& Cronin, 2001; Sureshchandar, Rajendran, \& Anantharaman, 2003). Additionally, recent studies show that the same effect exists when it comes to the service quality of SSTs and satisfaction with them. For example, a strong relationship between service quality in internet retailing and customer satisfaction was found by Wolfinbarger and Gilly (2003) and the same relationship exists when it comes to the satisfaction of customers in online consumer electronics (Wu, 2011). Also in the e-commerce industry, similar results were found (Ribbink, Riel, Liljander, \& Streukens, 2004).

There are some important factors that lead to satisfaction with SSTs. A study conducted explained that saving time and money, satisfy certain needs quickly and the possibility of avoiding employee contact were all important factors that led to satisfaction with SSTs (Meuter et al., 2000). In their study they also discuss that some of the main reasons that lead to dissatisfaction with technology are: incorrect functioning, SST unavailability, system errors and any type of SST failure.

In more recent studies, service quality of self-checkout systems in supermarkets was found to be directly related to customer satisfaction (Orel \& Kara, 2014). This shows us that service quality of SSTs that is evaluated using the SSTQUAL has an effect on customer satisfaction. This is of importance to this study because previous studies found results mainly relating to web-based SSTs or generally service quality.

The importance of studying the relationship between SST service quality and customer satisfaction lies in the fact that satisfied customers based on their satisfaction with the service will probably come back for more in the future. Satisfaction is associated with future financial returns for the organization because a satisfied customer leads indirectly to more future purchases (Anderson et al., 1994).

Accordingly, we propose the following hypothesis:

H1: XTM service quality has a positive effect on customer satisfaction.

\subsection{Customer Satisfaction and Customer Loyalty}

In the literature there are various studies which indicates the relationship among customer satisfaction and customer loyalty. However, studies are inconsistent. While customer loyalty in some studies has been found to have a direct relationship with service quality (Boulding, Kalra, Staelin, 1993); in other studies no direct relationship could be found between service quality or SST service quality and customer loyalty (Orel \& Kara, 2014; Cronin and Taylor, 1992). For example, Sivadas and Baker (2000) suggested that customer loyalty is the main goal of customer satisfaction measurement.

Accordingly, we propose the following hypothesis:

H2: Customer satisfaction has a positive effect on customer loyalty.

\subsection{SST Service Quality and Customer Loyalty}

Customer loyalty is considered a very important factor for service providers because it increases the willingness of customers to buy products and recommend it to others. Customer loyalty can be defined as an attitude that causes the customer to repeatedly buy products or services of the company and also recommend such products or services to others (Pearson, 1996). Others define it a word-of-mouth recommendation to others and a tendency buy more than once from the same company (Lee, Lee, \& Feick, 2001).

Customer loyalty defined as repurchase intentions was found to be not as affected by service quality as customer satisfaction; while still being affected indirectly through customer satisfaction which has a direct relationship with repurchase intentions (Cronin \& Taylor, 1992). On the other hand, service quality was found to have a direct relationship with repurchasing intentions and willingness to recommend. In a more recent study, SST service quality was found to directly affect customer satisfaction which in turn affect customer loyalty but no direct relationship was found between customer satisfaction and customer loyalty (Orel \& Kara, 2014). Other studies that used SSTQUAL focused more on studying the relationship between SST service quality and behavioral intentions (Lin \& Hsieh, 2011; Radomir \& Nistor, 2012, 2014).

Different opinions about the relationship between SST service quality - service quality- and customer loyalty shows that there is a need to conduct more studies about the relationship between SST service quality and customer loyalty and find 
out whether there is a direct relationship between them or not. The fact that a relationship between them may not exist makes it important to find out if there is an indirect relationship as a result of customer satisfaction's effect on customer loyalty.

Furthermore, customer satisfaction was found to have a mediating effect on the relationship between service quality and customer loyalty (Akbar \& Parvez, 2009). This may be the reason why many studies have failed to find a direct relationship between SST service quality and customer loyalty while customer satisfaction is present.

Accordingly, we propose the following hypothesis:

H3: Customer satisfaction has a mediating effect on the relationship between XTM service quality and customer loyalty.

Figure 1: Conceptual Model

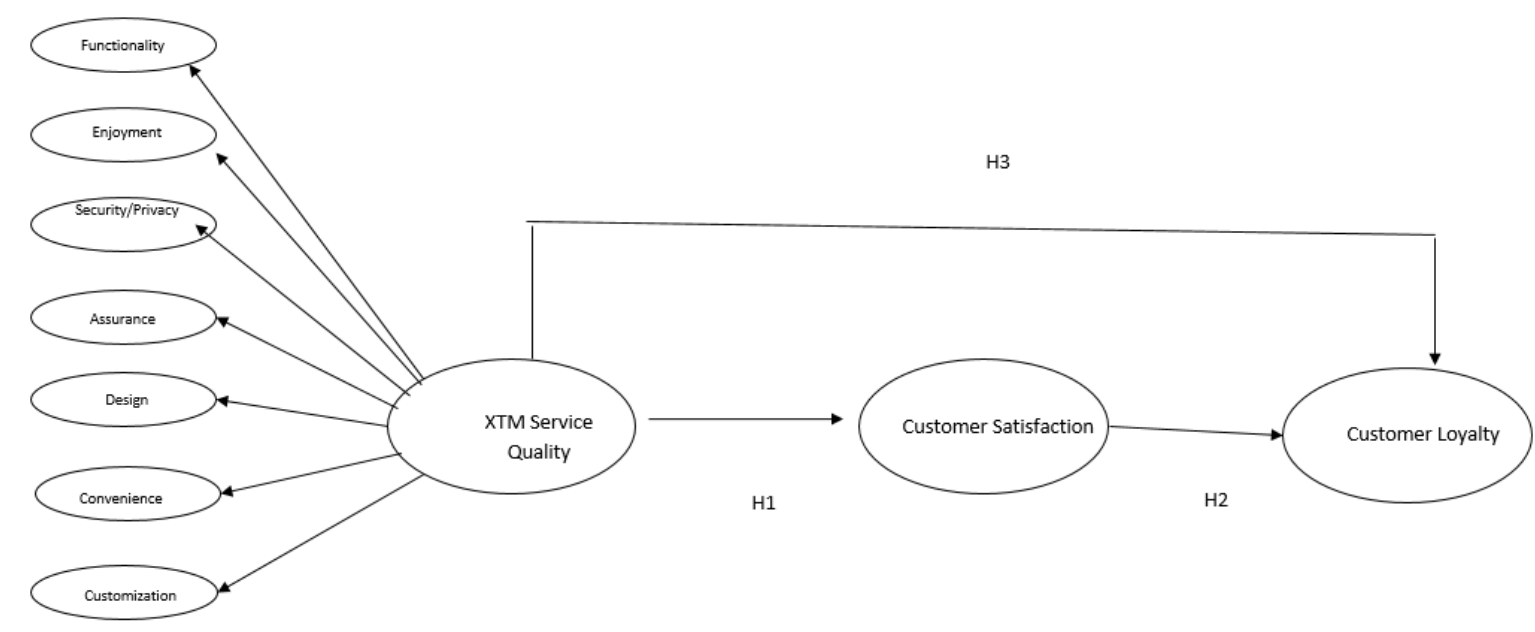

\section{RESEARCH DESIGN}

\subsection{Sample and Data Collection}

In order to test the research model, one hundred and sixty five XTM's customer were surveyed through online survey tools. Typeform.com was chosen as the survey tool because of user friendly design and many other functions that were necessary in assuring the quality of the data collected. The final survey was uploaded to typeform.com and the survey's link was given to the bank to be sent to XTM customers. Of the 165 total number of respondents $68,5 \%$ were male and $31,5 \%$ were female users. The respondents age were between 26-35 (61\%) and have bachelor degree (93,9\%).

The questionnaire was composed of four parts; the first section of the distributed survey was made up of 20 questions for measuring XTM quality. The second section contained questions measuring customer satisfaction and loyalty. The third and final section contained general demographic questions. We adapted items from prior studies and all items were measured level Likert-type scales from 1 (strongly disagree) to 7 (strongly agree).

\subsection{Measures}

Self-service technology quality SSTQUAL was measured using 20 items including seven dimensions; namely are functionality, enjoyment, security, assurance, design, convenience, and customization, adapted from Orel and Kara (2014). An example item is I feel good being able to use the XTM.

The second set of customer satisfaction and loyalty questions were a total of 9 questions ( 4 and 5 respectively.) The questions for measuring customer satisfaction were adapted from (Bloemer, Ruyter, \& Peeters, 1998); while the customer loyalty questions were adapted from (Cronin et al., 2000). As for the third demographics section, it contained questions about: age, gender, education, frequency of banking, frequency of using XTM and monthly income. These questions were found to be useful in previous studies of this kind which is why we decided to include them. Also, these questions helped us learn more about the survey participants and the users of XTM.

After translating the survey into Turkish, a focus group was conducted with experts in the field of User Experience in the banking industry. The objective of this focus group was to make sure that these questions will be understood correctly by 
users (customers) of the XTM. Based on this focus group some minor changes were made to the wording of some of the questions in the survey.

Finally we distributed the survey to 5 XTM users and asked them to share their thoughts and comments about the questions and what they understood from them. After this field test, it was concluded that the questions will be easily understood by the customers and are ready to be distributed. However both the participants in the field test and the focus group noted that the second security item (SEC2) which asks about the XTM's privacy policy is not completely understandable. Nonetheless it was used in the survey and this feedback was taken into consideration in data analysis.

After making the necessary modifications to the survey, it was ready to be distributed for purposes of data collection.

\section{ANALYSIS AND DESIGN}

\subsection{Measure Validity and Reliability}

After data collection process, we evaluated reliability and validity of measures. KMO $(0,941)$ and significance value $(p=0.00)$ shows that our sample is suitable for the factor analytic process. In order to examine factor structure we performed confirmatory factor analysis by using structural equation modelling (SEM). During CFA, two items were found to be nonconforming with our model and thus were removed in order to improve the general model fit. These items were ENJ4 from the Enjoyment factor and SAT4 from the Customer Satisfaction factor. After elimination of the two items, the measurement model fits the data well, $\chi 2 / \mathrm{df}$ is below 3 which is a reasonable fit (Marsh \& Hocevar, 1985). The comparative fit index also shows good fit (Bentler \& Stein, 1992). The incremental fit index (IFI=0.911) and the Tucker-Lewis index $(T L I=0.900)$ also show good fit. Finally the root mean square error of approximation (RMSEA=0.083) is within the acceptable limit (Browne \& Cudeck, 1992). The parsimonious normed fit index (PNFI=0.754) is also above 0.7. In addition, the standardized factor loadings were estimated and validity was checked. The standardized factor loadings can be found in Table 1. All factor loadings are significant and above 0.7 with the exception of DES2 that has a loading of 0.662 which also acceptable. In turn, this indicates convergent validity (J. C. Anderson \& Gerbing, 1988).

We also calculated the coefficient alphas, average variance extracted (AVE) and the composite reliability (CR) for all the variables, see Table 1

Table1: Correlation Validity and Reliability Coefficients

\begin{tabular}{|l|l|l|l|l|l|l|l|l|l|l|}
\hline Variables & & 1 & 2 & 3 & 4 & 5 & 6 & 7 & 8 & 9 \\
\hline Functionality & 1 & $(.83)$ & & & & & & & & \\
\hline Enjoyment & 2 & $0.57^{* *}$ & $(.83)$ & & & & & & & \\
\hline Security/Privacy & 3 & $0.69 * *$ & $0.54^{* *}$ & $(.77)$ & & & & & & \\
\hline Assurance & 4 & $0.51^{* *}$ & $0.37^{* *}$ & $0.49^{* *}$ & $(.85)$ & & & & & \\
\hline Design & 5 & $0.49^{* *}$ & $0.47^{* *}$ & $0.59^{* *}$ & $0.49 * *$ & $(.68)$ & & & & \\
\hline Convenience & 6 & $0.52^{* *}$ & $0.46^{* *}$ & $0.6 * *$ & $0.45^{* *}$ & $0.66^{* *}$ & $(.72)$ & & & \\
\hline Customization & 7 & $0.57^{* *}$ & $0.43^{* *}$ & $0.69 * *$ & $0.43^{* *}$ & $0.57^{* *}$ & $0.73^{* *}$ & $(.87)$ & & \\
\hline Satisfaction & 8 & $0.43^{* *}$ & $0.33^{* *}$ & $0.45^{* *}$ & $0.69 * *$ & $0.45^{* *}$ & $0.5^{* *}$ & $0.42^{* *}$ & $(.89)$ \\
\hline Loyalty & 9 & $0.43^{* *}$ & $0.38^{* *}$ & $0.42^{* *}$ & $0.58^{* *}$ & $0.37^{* *}$ & $0.4^{* *}$ & $0.34^{* *}$ & $0.68^{* *}$ & $(.90)$ \\
\hline Mean & 5.36 & 5.82 & 5.15 & 5.86 & 5.46 & 5.39 & 4.96 & 5.97 & 6.18 \\
\hline
\end{tabular}




\begin{tabular}{|l|l|l|l|l|l|l|l|l|l|l|}
\hline Standard Deviation & & 1.27 & 1.24 & 1.31 & 1.13 & 1.21 & 1.16 & 1.40 & 1.09 & 1.07 \\
\hline AVE & & 0.69 & 0.69 & 0.59 & 0.72 & 0.47 & 0.52 & 0.76 & 0.79 & 0.81 \\
\hline $\begin{array}{l}\text { Composite } \\
\text { Reliability }\end{array}$ & 0.92 & 0.87 & 0.74 & 0.84 & 0.64 & 0.68 & 0.91 & 0.92 & 0.95 \\
\hline Cronbach Alpha & 0.92 & 0.87 & 0.74 & 0.83 & 0.64 & 0.67 & 0.90 & 0.92 & 0.95 \\
\hline
\end{tabular}

$* * p<0.01$

Note: Numbers on diagonals represent the square root of AVE.

All the measures are either above or very close to the limitations provided by the literature (Fornell \& Larcker, 1981). All AVEs are above the recommended 0.5 level suggested by Bagozzi, Yi and Singh (1991); except for Design (AVE $=0.47$ ) which also very close to the limit. The AVEs also show acceptable levels of discriminant validity (Demirci Orel \& Kara, 2014). However, we also notice that all correlations of the Design factor are below the square root of AVE. As for the correlations, they are all below the corresponding square root of AVE except for the correlation of Customization and Convenience (0.73) which is very close to the square root of AVE (0.72). Also, the results show us that all the dimensions have a Cronbach's alpha that is greater than 0.7 which is the recommended threshold in the literature (Kline, 2005); however Design and Convenience are a bit lower than the threshold but are still very close to the minimum requirement. In addition, it is common to see lower than 0.7 reliability coefficients for dimensions with less than 10 items (Pallant, 2007).

\subsection{Hypothesis Testing}

In order to investigate the relationship among self-service technology quality, customer satisfaction and customer loyalty we used structural model.

The first hypothesis which states that there is a positive effect of XTM service quality on customer satisfaction is supported with $(\beta=.710 p<.01)$. This shows us that customers who are satisfied with the SST are also more likely to have evaluated the XTM service quality as high. This is important for managers because any increase in the XTM service quality directly leads in an increase in customer satisfaction.

As for the second hypothesis we hypothesize that customer satisfaction has a direct effect on customer loyalty is also supported with $(\beta=710 \mathrm{p}<.01$ ). Thus we find that similar to the literature, there is a direct effect of customer satisfaction on customer loyalty.

Finally, the third hypothesis which states that customer satisfaction is a mediator in the relationship between XTM service quality and customer loyalty is also supported. First, we showed that the independent variable i.e. XTM service quality directly affects the mediator which is customer satisfaction; this was supported in the first hypothesis. Second, we show that the independent variable (XTM service quality) directly impacts the dependent variable i.e. customer loyalty; this was supported in the second hypothesis. Third, we show that the mediator (customer satisfaction) directly impacts the dependent variable (customer loyalty) and that when the mediator is kept in the path analysis, the relationship between the independent variable (XTM service quality) and the dependent variable (customer loyalty) no longer is supported. Accordingly, we have proved that the third hypothesis is also supported because of the effects explained above which were based upon the model for testing mediator effects (Baron \& Kenny, 1986) as shown in Table 2.

As we saw above, XTM service quality was found to have a direct impact on customer satisfaction. These results are in accordance with previous literature and theory; thus indicating that the model also has good predictive validity (Bagozzi, Yi, \& Phillips, 1991). Additionally, customer satisfaction was found to affect customer loyalty and mediate the effect between it and XTM service quality. This is very important for any service provider because retaining customers and increasing their loyalty is one of the most important goals of any service provider. The cost of gaining a new customer is much higher than retaining a customer who has already been satisfied by your service (Reichheld \& Schefter, 2000). Also, because all the dimensions of SSTQUAL were found to be valid and strongly affect XTM service quality, service providers should also take special care in providing for the 7 dimensions of quality found in SSTQUAL. 
Table 2. Results of mediating hypothesis.

\begin{tabular}{|l|l|l|l|}
\hline Path & Model a & Model b & Model c \\
\hline XTM Service Quality -> Customer Loyalty & $0,60^{* * *}$ & & \\
\hline XTM Service Quality -> Customer Satisfaction & & $0,71^{* * *}$ & \\
\hline $\begin{array}{l}\text { XTM Service Quality -> Customer Loyalty } \\
\text { XTM Service Quality -> Customer Satisfaction } \\
\text { Customer Satisfaction -> Customer Loyalty }\end{array}$ & & & $-0,60$ \\
\hline
\end{tabular}

$* * * p<0.01$

\section{DISCUSSION}

The aim of this study was to first test whether the SSTQUAL model developed by Lin and Hsieh (2011) is replicable and valid in the participation banking industry in Turkey when applied to a new type of technology called XTM (an advanced type of VTM). Also, it aimed at testing whether a relationship exists between the evaluation of customers of the XTM service quality and customer satisfaction and loyalty.

We concluded that the model that consists of SSTQUAL quality dimensions, customer satisfaction and customer loyalty is a valid model that was replicated in a different industry (i.e. participation banking), a different culture (i.e. Turkey) and a different type of SST i.e. XTM. This was an important step because to the best of our knowledge this has not been performed before in the same conditions.

Furthermore, we supported literature that studies the relationships between SST service quality, customer satisfaction, and customer loyalty. We found that the XTM service quality does have a direct impact on customer satisfaction and customer loyalty.

As for practical implications, companies who use SSTs can benefit from applying the SSTQUAL model to evaluate customers' perceptions of the quality of the SST. This study also showed that generally speaking many people are getting used to using SSTs in daily life and are overall satisfied with such technology and accordingly satisfied with the companies who provide the SST. Management should realize the importance of SSTs for gaining competitive advantage over other banks through providing customer satisfaction and loyalty.

Our suggestion for further research is that this scale should be expanded item-wise and should contain a list of different variables and dimensions. For example, the impact of SSTQUAL on firm financial performance can be investigated.

Finally, the main limitation of this study was the population and sample at hand. The XTM is a very new type of SST and state-of-the-art technology which is only used by KTPB. To the best of our knowledge, there are no banks in Turkey that use the same technology. Thus, surveys were only distributed to users of the XTM that is used by KTPB. This led to having a small sample size and prevented us from applying this survey and model across different banks in Turkey.

\section{REFERENCES}

Akbar, M. M., Parvez, N. 2009, "Impact of service quality, trust, and customer satisfaction on customers loyalty", ABAC Journal, vol.29, no:1, pp.24-38.

Akhisar, İ., Tunay, K. B., Tunay, N., 2015, "The Effects of Innovations on Bank Performance : The Case of Electronic Banking Services," World Conference on Technology, Innovation and Entrepreneurship, 195, pp. 369-375.

Anderson, E. W., Fornell, C., Lehmann, D. R. 1994, “Customer Satisfaction, Market Share, and Profitability: Findings from Sweden”, Journal of Marketing, vol.58, no.3, pp. 53-66.

Baron R., Kenny D.1986. "The moderator-mediator variable distinction in social psychological research", Journal of Personality and Social Psychology, vol:51 no:6, pp. 1173-1182.

Boulding, W., A. Kalra, R. Staelin, V. A. Zeithaml, 1993, A Dynamic Process Model of Service Quality: From Expectations to Behavioral 
Intentions." Journal of Marketing Research, vol: 30, pp.7-27.

Brady, M. K.,Cronin, J. J. J. 2001, "Some New Thoughts on Conceptualizing Perceived Service Quality: A Hierarchical Approach" ,Journal of Marketing, vol.65, pp.34-49.

Cronin, J. J., Brady, M. K., Hult, G. T. M. 2000, “Assessing the Effects of Quality, Value, and Customer Satisfaction on Consumer Behavioral Intentions in Service Environments, Journal of Retailing, vol. 76, no.2, pp. 193-218.

Dabholkar, P.A.,1996, “Consumer Evaluations of New Technology-Basedself-Service Options: An Investigation of Alternative Models of Service Quality, International Journal of Research in Marketing ,vol.13, no. 1, pp. 29-51.

Howcroft, B., Hamilton, R., Hewer, P. 2002, “Consumer Attitude and the Usage and Adoption of Home-Based Banking in the United Kingdom, International Journal of Bank Marketing, vol. 20, no.3, pp.111-121.

Hsieh, C. 2005, "Implementing Self-Service Technology to Gain Competitive Advantages", Communications of the IIMA, vol. 5, no.1, pp.7783.

Johnson, M. S., Sivadas, E., Garbarino, E. 2008, "Customer Satisfaction, Perceived Risk and Affective Commitment: An Investigation of Directions of Influence, Journal of Services Marketing, vol. 22 no.5, pp. 353-362.

Khalilov C., M., Gündebahar, M., 2012, “XTM : An Alternative Delivery Channel in Turkish Banking Sector" International Conference on Asia Pasific Business Innovation and Technology Management, 57, pp.373-380.

Lee, J., Lee, J., Feick, L. 2001, "The Impact of Switching Costs on the Cstomer Satisfaction-Loyalty Link: Mobile phone service in France" Journal of Services Marketing, Vol.15, no.1, pp.35-48.

Lin, J. S. C., Hsieh, P. L. 2011. "Assessing the Self-service Technology Encounters: Development and Validation of SSTQUAL Scale”, Journal of Retailing, vol.87, no:2, pp. 194-206

Meuter, M.L.,Ostrom,A.L.,Roundtree,R.I.,Bitner,M.J.,2000, "Self-service technologies: Understanding Customer Satisfaction with Technology-Based Service Encounters", Journal of Marketing, 64, pp.50-64.

Pearson, S. 1996, “Building Brands Directly: Creating Business Value from Customer Relationships”. MacMillan Press Ltd.

Radomir, L., Nistor, C. V. 2012, "High-Educated Consumer Perceptions of Service Quality: An Assessment of the SSTQUAL Scale in the Romanian Banking Industry". Procedia Economics and Finance, vol.3., no:12, pp. 858-864.

Ribbink, D., Riel, A. C. R. Van, Liljander, V., Streukens, S. 2004, “Comfort Your Online Customer: Quality, Trust and Loyalty on the Internet. Managing Service Quality, vo.I14, no.6, pp. 446-456.

Sivadas, E., Baker-Prewitt, J. L. 2000. “An Examination of the Relationship between Service Quality, Customer Satisfaction, and Store loyalty",International Journal of Retail \& Distribution Management, vol,28, no:2, pp.73-82.

Sureshchandar, G. S., Rajendran, C., Anantharaman, R. N. 2003, "Customer Perceptions of Service Quality in the Banking Sector of Developing Economy: A Critical Analysis", International Journal of Bank Marketing, Vol.21, no:5, pp. $233-242$.

Wendy W.N. Wan, Chung-Leung Luk, C. W. C. C. (2005). Customers' adoption of banking channels in Hong Kong. International Journal of Bank Marketing, 23(3), 255-272.

Wolfinbarger, M., Gilly, M. C. 2003. "eTailQ: Dimensionalizing, Measuring and Predicting Retail Quality", Journal of Retailing, Vol.79, no:3, pp. 183-198.

Wu, K.W.,2011, "Customer Loyalty Explained by Electronic Recovery Service Quality: Implications of the Customer Relationship ReEstablishment for Consumer Electronics E-Tailers", Contemporary Management Research, Vol.7, no:1, pp. 21-43.

Yusuf, S., Lee, J., 2015, "Technology Adoption : A Conjoint Analysis of Consumers ATM Preference on Future Online Banking Services", Information Systems, 53, pp. 1-15. 